Note

\title{
Good practice: Honors activities within regular minor program
}

\author{
Brigitte van Barneveld
}

Staff member Honors program bachelors, Institute of Human Movement Studies, HU University of Applied Sciences Utrecht, The Netherlands.

Correspondence: brigitte.vanbarneveld@hu.nl

Received: 3 August 2018; Accepted: 13 December 2018; Published: 7 January 2019

Keywords: minor, honors program, active relation with work field

Note to reader: honors keywords (see introductory article of this issue) in italics in the text

\section{Introduction}

Some bachelor students doing a minor want to learn more than just the regular program offers. For those honors students, a practical model has been developed for honors activities and a real world (authentic) challenging assignment on top that is related to the activities in the eight minor programs of the Institute of Human Movement Studies at HU University of Applied Sciences Utrecht, The Netherlands. Central in this extra-curricular honors program are projects and assignments from the professional field, from one of the researchers (research centers), or from the educational program itself. Students are stimulated to make their own choice, and they can also develop their own project.

The development of the honors program and the guidance of the honors students during the program do require extra effort, but teachers and students alike are enthusiastic about the opportunities.

\section{Why this good practice?}

Honors teachers noticed that some students are looking for extra challenges. They explored the possibilities to perform an additional authentic, challenging, broadening, or in-depth project and assignment next to the regular curriculum. Teachers have to be able to differentiate to offer honors students extra and other challenging activities during the regular program. Differentiation requires insight into the needs of different students. Teachers find differentiation within regular courses difficult for multiple reasons: they spend little time with students (eight weeks) and they focus on preparing the whole group for the test and assignment at the end of the regular course.

Students choose a minor in the last phase of their disciplinary bachelor curriculum. A minor is a semester of specialization to deepen knowledge and skills in a specific area. Students can 
choose from all minors offered within the university. A small team of teachers (four) is responsible for a specific minor program. Guest speakers are also flown in. The setting is like a learning community and is ideal for giving room for an extra honors project and honors activities during the program, including a real world assignment on top.

Most students choose a minor that is related to the major of their bachelor curriculum. During minors, a small group of teachers (approximately four) supervises a group of about 25-30 students continuously during six months within a program that matches the affinity of the students and the teachers. This offers teachers the opportunity to get to know the students well and invest time in them. An honors minor provides for optional extra activities (deepening and/or broadening authentic project and assignments). Therefore, the minor is the perfect place to offer students extra honors activities embedded in the minor of the regular program.

\section{Target group and target group size}

Students can apply for an honors project before starting or during the first weeks of the minor. They spend an additional 100-140 hours (about 5 ECTS) while taking the minor consisting of 30 ECTS. This includes preparation time and time to write a report afterwards for the star request of the honors system of HU University of Applied Sciences Utrecht (Riteco, Kleyn, \& Lamerichs, 2017).

\section{Educational design (structure)}

There is a basic design, the 'model,' for honors activities in minors, which is represented in Figure 1.

Figure 1: Honors within minors

\section{Honours within minors}

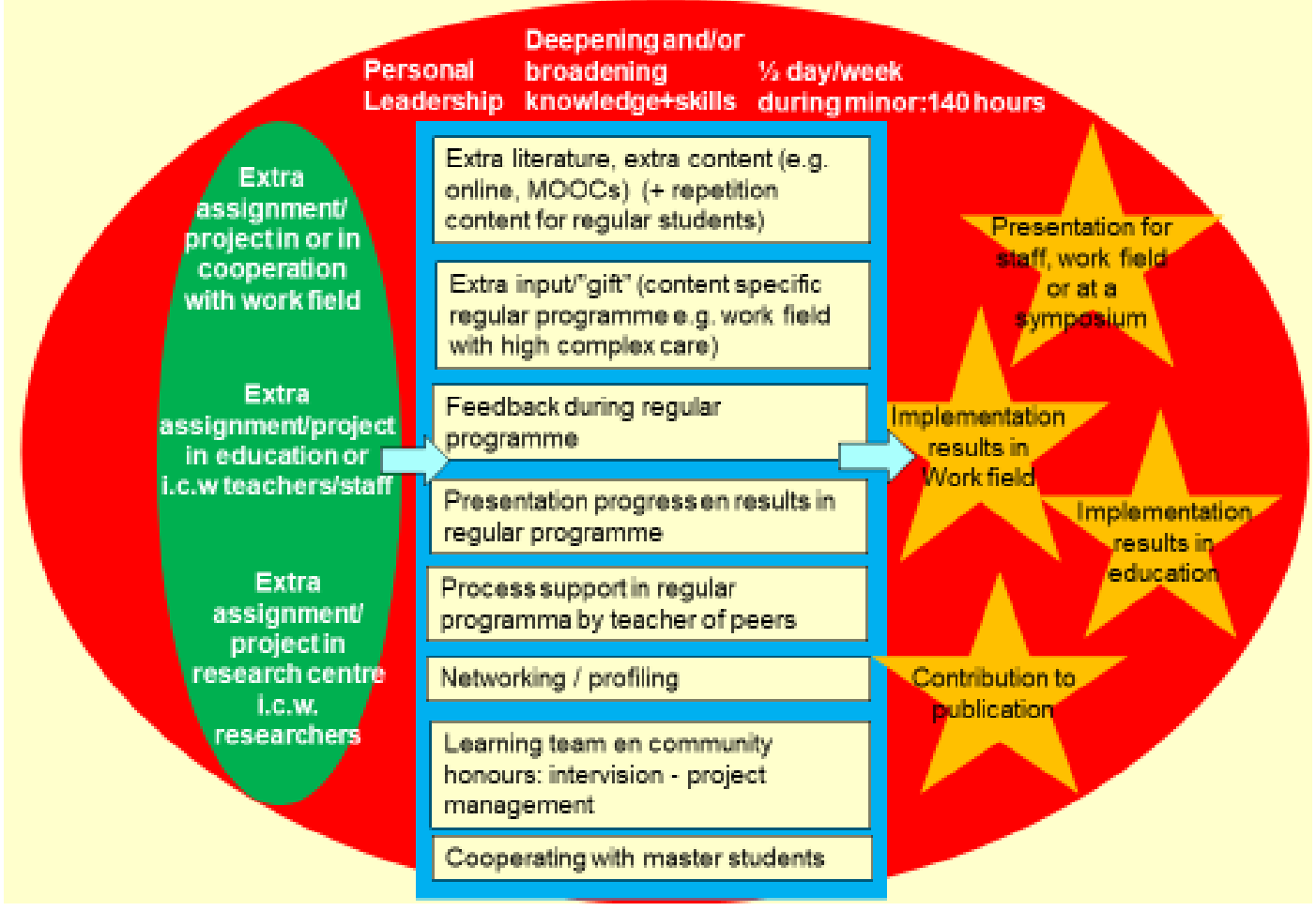

Source: Author

Journal of the European Honors Council 2019, 3(1), 4 
On the left in the green part of Figure 1 is the extra authentic challenging projects and assignments for the honors program gathered or prepared by the honors teachers. The blue part in the middle is the honors activities of the students during the honors minor, with some of them embedded in the regular minor. Personal leadership and deepening and broadening knowledge and skills are leading goals (within the half a day per week time available). The yellow stars reflect the results of students' honors activities. The arrows show the flow from extra projects and assignments to deepening and/or broadening of knowledge and skills, resulting in extra stars (competences). Each part of this model will now be explained further.

\section{Green part:}

The coordinator of the minor develops a parallel program of approximately half a day a week (with no official ECTS linked to it) to facilitate challenging deepening / broadening for students in a relevant professional practice, either in one of the research centers linked to the minor and / or an educational project. The program leaves room for the students' own wishes and contributions (creativity); they can also design their own project.

The available projects, based on input from the professional field, the research centers, or the education programs, are presented three months prior to the start. These projects need to be valuable to the client concerned, challenging, inspiring and instructive for the honors student, and fitting the honors approach well (giving room for creativity and responsibility). The interested honors students apply for a project and register, preferably before the minor starts. Students and projects are matched, considering the needs and preferences of both the student and the (external) partners involved. The chosen set-up focuses on a range of challenging opportunities for students instead of a fixed program.

\section{Blue part:}

Teachers in the minor need to create time and extra challenge for the honors students within their lectures and meetings. They offer extra or other (e.g. more in-depth and complex) content or other or extra assignments or products for some of the students. They make some changes (more flexible) in the structure and organization of their regular minor program, including time for extra personal coaching.

For example, homogeneous groups work on different assignments or on the same assignments but at different level, or they work in heterogeneous groups where the honors students coach the other students. The approach chosen also depends on what the students want to learn. Honors students are allowed to present their progress, to request and receive feedback, and to share their honors experiences with their fellow students. Honors students choose their own projects (green part) but are working together with other regular or honors students on project management issues, sharing experiences, sharing feedback, coaching, and intervision. Honors students of various minors can connect and build an honors community.

The eight minors are connected to research groups and master programs on the same subjects and themes, offering interesting opportunities for the honors students, like, for example, working together with researchers and master's students. 
The blue part challenges not just honors students but honors teachers, too. The differentiating didactics wished for are necessary to fully implement the honors program into the regular minor program. In other words, if the teachers are able to differentiate, honors within minors will be more successful.

\section{Student assessment}

The stars in the figure refer to the extra and challenging real-world assessment. At the end of this honors program, the student presents his or her results to the teaching team, the research group, the related work field, and / or fellow students during a symposium, a congress, or in a publication. With sufficient results, which means with enough value for the people involved, a student can earn a 'star' that can contribute to his or her honors certificate (Riteco, Kleyn, \& Lamerichs, 2017).

\section{Experiences}

Both students and teachers were immediately enthusiastic about the idea of honors projects embedded in the minors. It seems logical that this form of honors education should be available, but the investment in terms of time and effort is substantial. Contacts with the professional field and the research group need to be formalized, so that a continuous flow of projects and assignments can be assured. If a project exceeds the time frame of the minor, attention should be given to the transfer of projects / assignments to subsequent honors students for next year. Joining an honors program remains a free choice for students, and, therefore, there must be room for personal creativity and responsibility. This also implies a challenge for the teachers. In daily life, however, it turns out to be difficult to take into account all the wishes of honors students.

The biggest challenge for most of the teachers is to apply differentiating didactics in the meetings. It is a totally new experience that requires starting with small steps, sharing good practices, visiting each other's lessons to give or get feedback, and becoming more confident and getting used to it. In fact, some of the teachers say that a new world opens up for them. After some trials, they say that it is fun to work with different groups in the meetings and to invest much more time in the content and organization of their lessons. This leads to giving room to honors students and giving room to the differences between students and appreciating them. These differences are not necessarily between weak or strong students but between being well or not prepared for the meetings, conceptual thinkers-practitioners, learning patterns, etc.

\section{Time requirement for teachers}

The first time this honors program was organized, extra time had to be invested in discussing the honors program to check opportunities for projects / assignments and building the educational structure. This has to be done in collaboration with partners in the professional field and in the research groups and will cost a few days.

The second time, a couple of hours are needed for each lesson to search and develop indepth and / or broadening content, authentic challenging assignments, new feedback forms (peer, tutor, or digital feedback instruments) and a new organization of the meetings. When 
this new approach is adopted, the teachers have to get acquainted with it and build trust in applying differentiating didactics in this new form of education.

\section{Tips for teachers}

Some lessons have been learned already (see section 6). Prepare yourself well, share experiences with fellow teachers in the same program, visit each other's lessons, make video recordings, and exchange feedback instruments and organizational forms, making it possible to differentiate. A good practice approach, in which teachers exchange examples of projects / assignments that deepen/broaden knowledge and skills presented in the online learning portal, is advised. Elsewhere in this environment, repeat assignments can be incorporated to get the other students to work during feedback moments for the honors students.

\section{Tips for students}

Reserve time and space for honors (at least half a day each week), make time and space to reflect on what you as a student want to deepen and / or broaden in your honors trajectory. Your intrinsic motivation must be high if you want real, in-depth progress and completion of the project to the satisfaction of the client (other people concerned) and yourself.

\section{Transfer to other programs}

I would like to recommend this approach because it provides a practical, flexible way of substantial and relevant honors activities next to the regular program and is appreciated by both teachers and students. Related professional field experts and research centers are interested to work together on their own projects related to the minor program with extra motivated students and teachers.

The program will also be used in our new regular, more flexible curriculum in which we will work with larger learning units, making it possible to get to know the students better. Transfer (from elements of the green or blue part) to other honors programs or regular programs is a good possibility, too.

\section{References, additional information, and relation with Circle of Talent Development}

\section{$\underline{\text { References }}$}

Riteco, A., Kleyn, I. de \& Lamerichs, N. (2017). Honours and (re)design of the curriculum: How to bridge the gap between honours and bachelor programmes. Journal of the European Honors Council 1(1), 11. https://doi.org/10.31378/jehc.47

\section{Relation with Circle of Talent Development}

In the introductory article of this issue of JEHC, the 'Circle of Talent Development' has been described. Based on interviews with forty honors students and literature about honors programs, it reflects relevant activities of students regarding the development of their talents in an honors program. The author of this note has been asked to score the good practice in relation to the activities in the Circle of Talent Development. The meaning of the 
scores is: + = somewhat important; ++ = moderately important; +++ = very important; - = not applicable or irrelevant. The scores are intended to illustrate the strengths of a good practice for the reader.

Figure 2. Circle of Talent Development in relation with the good practice 'Honors activities within regular minor program' with the teacher's scores

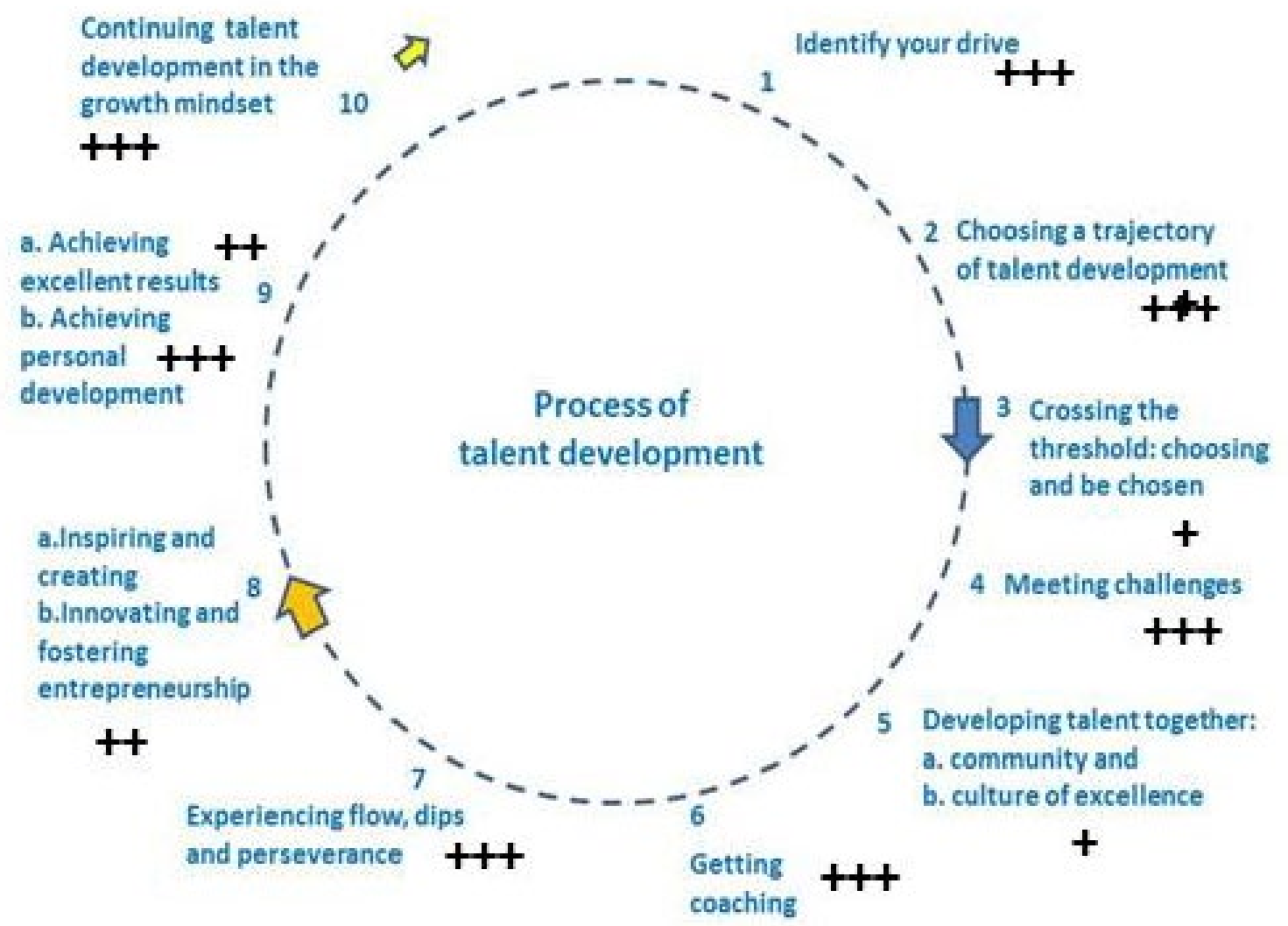

Question to the teacher: What makes this good practice attractive for other teachers?

The teacher of this practice argues: 'They can easily use the format and adapt/translate it for their own context and content.' 